\title{
Mediación, garantías y seguridades internacionales: El caso del PNV en la rendición de Bilbao (1937)
}

\author{
Dr. Antonio Marquina*
}

NOTA PRELIMINAR

La investigación realizada hasta el momento sobre las relaciones entre la Santa Sede y el Partido Nacionalista Vasco (PNV), antes de la rendición de Bilbao, es bastante amplia y documentada. No obstante, al revisar las versiones hasta ahora realizadas, tanto por historiadores como por protagonistas, existen diversos puntos no suficientemente aclarados o versiones que permiten una diferente interpretación. Este ha sido el caso del reciente estudio del profesor Fernando de Meer sobre la mediación del Vaticano para la rendición de Bilbao.

En este estudio nuestro, tratamos de abordar en una perspectiva de conjunto el problema creado a la diplomacia vaticana por la posición política adoptada por el PNV durante 1937 hasta la caida de Bilbao, aportando nuevos datos que sirven para explicar la continuidad de las propuestas de mediación y las dificultades de aceptación por parte del PNV, así como la diversidad de actores y percepciones.

\section{INTRODUCCIÓN}

EI PNV habia adoptado una postura contraria al «alzamiento nacional» desde el inicio de la guerra civil, manteniendo su apoyo al gobierno re-

\footnotetext{
* Profesor de Relaciones Internacionales. Facultad de CC. Políticas. Universidad Complutense.
} 
publicano. Dada la tremenda persecución religiosa en la zona republicana, esta actitud se consideró difícilmente aceptable desde el punto de vista religioso. Los obispos de Vitoria y Navarra desautorizaron esta posición el 6 de agosto de 1936 mediante una carta pastoral. A pesar de esta toma de posición, se fue desarrollando una gran animadversión contra el obispo de Vitoria y los sacerdotes que apoyaban el movimiento nacionalista vasco.

Ante la dureza de los combates en Guipúzcoa, la Junta de Defensa Nacional exigió la retirada de monseñor Mateo Múgica de la diócesis de Vitoria. Se le acusaba de haber amparado al movimiento nacionalista con su excesiva transigencia con los sacerdotes nacionalistas «principales culpables de este movimiento popular y con su acción positiva antes de entablarse la contienda».

La Santa Sede acabó por ceder, tras unas laboriosas negociaciones, y el 25 de septiembre indicó al cardenal Gomá la conveniencia de que monseñor Múgica se alejase de su diócesis.

Posteriormente tuvo lugar el fusilamiento expeditivo de catorce sacerdotes nacionalistas vascos, acusados de apoyar al nacionalismo vasco, dentro de un clima de represalias contra militantes y simpatizantes del PNV, que se produjeron en Guipúzcoa a medida que avanzó la conquista. Esto creó un precedente muy negativo para el posterior entendimiento entre el gobierno nacional y el PNV.

Esta animadversión, desplantes y represalias, que se unían a las noticias provinientes de otros frentes, ensamblada con el pésimo hacer diplomático del marqués de Magaz en Roma, explicará el ambiente de frialdad con respecto al bando nacional que el cardenal Gomá encontró en la Santa Sede con motivo de su visita de información en diciembre. El tema central de discusión fue la situación de la Iglesia en la zona nacional y la posible orientación de las autoridades del bando nacional con respecto a la misma ${ }^{1}$.

El informe remitido por el marqués de Magaz sobre los resultados de esta visita dejará malparado al cardenal Gomá en sus posibilidades de actuación en el tema del nacionalismo vasco. Según este informe, su actitud habia sido positiva para la rectificación de errores sobre el movimiento militar, pero negativa en lo referente a los nacionalistas vascos.

\footnotetext{
1 Sobre lo acontecido en estos primeros meses pueden consultarse diversas obras. Véase por ejemplo Granados, A., El cardenal Gomá (Madrid, Espasa Calpe, 1969). Marquina, A., La diplomacia vaticana y la España de Franco (1936-1945) (Madrid, CSIC, 1982). MARQUINA, A., "El Vaticano contra la Cruzada», Historia 16, 22 (1978) 39-52.
} 
En este punto le acusó de guardar «una condescendencia difícilmente explicable»? .

A su vuelta de Roma con el nombramiento como agente oficioso vaticano, se entrevistó el 29 de diciembre con Franco. El cardenal explicó los deseos de la Santa Sede contenidos en una carta reservada entregada por el secretario de Estado del Vaticano antes de su salida de Roma, en especial, la conveniencia de que la Iglesia lograra en el ejercicio de sus funciones «aquella libertad que es garantía de su eficacia, de la perfecta relación entre ambos poderes, y hasta del mismo bien temporal de la nación». El general Franco no opuso ningún reparo en este punto. Con respecto a los demás puntos de la carta y en especial los casos del obispo de Vitoria y el obispo de Canarias, la conversación fue más animada, intercambiándose argumentos y razones por ambos lados. Al final, preguntado el general sobre si tendria inconveniente en que se sintetizara por escrito la conversación para someterla a su aprobación, con el fin de dar más fuerza a la comunicación que debería enviar a la Santa Sede, el general asintió complacido. Por esta razón tuvo lugar una segunda entrevista en la que el cardenal Gomá fue leyendo el resumen de los diversos puntos que fueron aprobados sin reparo. El general Franco agradecía profundamente el nombramiento del cardenal Gomá como representante conficencial y oficioso de la Santa Sede y ofrecía corresponder a esta concesión manifestando su deseo de que las relaciones fuesen cada día más intimas y cordiales. Prometía que no se procedería en los asuntos de índole mixta de forma unilateral, sino de acuerdo con las autoridades eclesiásticas. En cuanto al nombramiento de Antonio Pildain para el obispado de Canarias no tenía inconveniente de que se procediera a su consagración, y por lo que respecta al obispo de Vitoria no insistía en su renuncia, pero habida cuenta de la exacerbación de las pasiones políticas en su diócesis, se rogaba a la Santa Sede que se difiriera sine die el regreso del prelado a su diócesis. Con respecto a los sacerdotes vascos tachados de nacionalistas, cuyo traslado a otras diócesis se había propuesto por el gobernador civil de la provincia de Guipuzcoa, de acuerdo con el gobierno de Burgos, se confiaba la resolución de este asunto al cardenal Gomá en conexión con el obispo de Vitoria y las anteriores autoridades. Final-

2 Archivo de la Embajada de España ante la Santa Sede (AEESS), despachos 1936, despacho $n .{ }^{\circ} 11$, Roma 21 de diciembre de 1936. El 29 de diciembre, en el despacho n. ${ }^{\circ} 14$, muy confidencial, el marqués de Magaz envió un envenenado informe resaltando que cuando llegó el cardenal Gomá se examinaba seriamente en el Vaticano la cuestión del reconocimiento, pero de las conversaciones del cardenal Gomá con el secretario de Estado y posiblemente de su punto de vista sobre la cuestión vasca surgió la idea de aplazar el reconocimiento y nombrar un agente oficioso. Nada más lejos de la realidad. 
mente el general Franco manifestó su propósito de modificar o derogar aquellas leyes que por su tendencia o por su letra fuesen disconformes con el sentido católico. El general Franco esperaba por todo ello el concurso moral y espiritual de la Santa Sede ${ }^{3}$.

\section{LA SANTA SEDE: ENTRE DIPLOMACIA Y REPROBACIÓN}

A partir de estas conversaciones con el jefe del Estado, el cardenal Gomá se entrevistó con el presidente del gobierno nacional, el general Dávila, con el señor Bau, con el general de la división de Burgos, López Pinto, y otras personalidades. El cardenal remitió a la secretaria de Estado un resumen de las impresiones y juicios de estas personalidades centradas en dos puntos: El deseo de que cuanto antes fueran reconocidos oficialmente por la Santa Sede y el problema planteado por los nacionalistas vascos que estaban luchando al lado de los rojos. Estos problemas, aunque reseñados por separado, tenían indudables conexiones. Todas aquellas autoridades manifestaban su contrariedad por no tener de su lado el enorme peso moral que representaba el reconocimiento de la Santa Sede, siendo así que el movimiento nacional «tenía por base la restauración de los factores de orden religioso" y el gobierno de Madrid representaba "el ateismo y la anarquia" ${ }^{4}$.

En este punto surgia la cuestión ¿Cómo era posible compaginar la actuación del gobierno de Madrid con el mantenimiento de la alianza de los católicos nacionalistas vascos a este gobierno? La alianza se consideraba como absolutamente inadmisible en buena moral católica y como ingenua desde el punto de vista de la oportunidad política. Los católicos del PNV, por su parte, se aferraban a la ilegitimidad del alzamiento y más tarde al fascismo del bando oponente, al ser ayudados por Italia y Alemania. Eran dos visiones diferentes del conflicto.

En Burgos y Salamanca se pensaba que la clave en la solución del problema se encontraba en la Santa Sede. Los asesinatos de obispos, sacerdotes, religiosos y católicos en general, habían hecho desaparecer, a su juicio, cualquier tacha legal o moral contra el alzamiento. Incluso más, habian servido de justificación a posteriori. El apoyo y el reconoci-

3 Archivo del cardenal Gomá (ACG), informes al cardenal Pacelli. Pamplona 31 de diciembre de 1936 y 1 de enero de 1937.

${ }^{4}$ ACG, informe al cardenal Pacelli. Pamplona 1 de enero de 1937. 
miento de la Santa Sede implicaria indirectamente la desautorización del PNV que no se avenía a un compromiso con el bando nacional. A estos razonamientos se añadía otro de indiscutible fuerza, la Santa Sede debía dejar bien clara su posición desautorizando las alianzas con los Frentes Populares y el comunismo, asunto este sobre el que no existian grandes discrepancias entre los católicos. El problema no se veía como un problema exclusivamente nacional. Desde Burgos se insistía a la Santa Sede en que el triunfo del bando nacional significaba el triunfo de la religión católica en Europa, desapareciendo la religión, en caso contrario, de España, Portugal y Francia a corto plazo ${ }^{5}$. Estas serán las líneas de fuerza de la argumentación ante la secretaría de Estado del Vaticano.

Así, tras el fracaso de la ofensiva de los nacionalistas vascos en Villarreal en diciembre de 1936, se trasmitió un telegrama al marqués de Magaz, vía Palma de Mallorca, desde la secretaría general del jefe del Estado, urgiendo a una condenación explícita de los católicos nacionalistas vascos "que debían excomulgarse, así como a todo el que directa o indirectamente ayudase a los rojos en España" ${ }^{6}$. Como apuntamos, se consideraba que la Santa Sede tenía en sus manos la pronta solución de la guerra de España. Estas gestiones «urgentes», dado «el estado moral vacilante» tras la derrota, se solicitaron también a todos los amigos y aliados del gobierno nacional en orden a presionar a la Santa Sede. Con este motivo, el marqués de Magaz visitó al cardenal secretario de Estado a quien entregó una copia literal de la primera parte del telegrama. El cardenal Pacelli la leyó atentamente en su presencia y refiriéndose a los católicos nacionalistas vascos dijo: «Es indudable que han cometido un delito. Consultaré el caso con el Santo Padre» ${ }^{7}$. El telegrama, al interesar también una gestión análoga de los gobiernos amigos dio pie a una gestión del encargado de negocios español ante el gobierno de Mussolini, pero ya el gobierno italiano había recibido directamente el ruego del gobierno nacional y había llevado a efecto el encargo. El embajador italiano ante la Santa Sede y el cardenal Pacelli mantuvieron a estos efectos una entrevista el 29 de diciembre. El cardenal explicó que la intransigencia de Franco, intransigencia que denotaba una falta de sentido político, había hecho imposible con anterioridad un acuerdo con los católicos del PNV, pero que ello no excusaba el delito que éstos estaban cometiendo ayudando a los rojos.

\footnotetext{
${ }^{5}$ AEESS, legajo 73, telegrama 141. Palma, 25 de diciembre de 1936.

${ }^{6}$ Idem, ibidem.

AEESS, despachos 1937, n. ${ }^{\circ}$ 16. Roma 9 de enero de 1937.
} 
Al día siguiente el embajador italiano informó que el Papa estaba dispuesto a intervenir, pero quería saber qué concesiones estaba dispuesto a hacer el general Franco ${ }^{8}$.

A su vez el general Franco insistió ante el cardenal Gomá. Una desautorización de la conducta de los vascos del PNV por parte de la autoridad eclesiástica podría ser un factor decisivo en el propósito de hacer desistir de la lucha, sobre todo en aquellos momentos de depresión tras la derrota de Villarreal. Franco decía que con menor motivo la lglesia había intervenido en otros tiempos en favor de la causa cristiana y contra las fuerzas enemigas de la religión. El cardenal Gomá paró esta iniciativa, conociendo el problema que se le presentaba a la Santa Sede. Por ello, ofreció al general sus oficios de mediador y le indicó incluso la posibilidad de que el propio obispo de Vitoria interviniera de nuevo desde Roma ratificando el contenido de la pastoral de 6 de agosto, añadiendo que haría presentes a la secretaría de Estado los puntos de vista del jefe del Estado en orden a una mejor resolución del problema. Es en este despacho al cardenal Pacelli donde el cardenal Gomá presentó el proyecto de carta abierta al presidente Aguirre para insistir en las razones alegadas en la anterior carta pastoral de los obispos de Navarra y de Vitoria. El motivo era un discurso que había pronunciado el máximo dirigente del PNV en Bilbao dendo hacía serias acusaciones a la jerarquía católica. El cardenal Gomá presumía que no tendria eficacia alguna -así lo dice expresamente al cardenal Pacelli- como no la tuvo el anterior documento pastoral ${ }^{9}$.

La Santa Sede se encontraba ciertamente ante un problema muy espinoso y las presiones eran fuertes. La situación se fue haciendo cada vez más embarazosa.

La contestación vaticana a las gestiones italianas fue conocida por el marqués de Magaz rápidamente. Algo perplejo por el contenido no se atrevió a telegrafiario hasta conocer la respuesta de la secretaría de Estado a la petición española. Con este fin solicitó una audiencia y fue recibido el 7 de enero por el cardenal Pacelli quien le indicó que todavía estaba en estudio la petición española, a lo que el agente oficioso manifestó que se habia hecho una gestión semejante por el gobierno italiano y ya se habia dado respuesta. El cardenal replicó con cierta ironía que, en efecto, se trata de una petición mucho más suave, y que seguian es-

\footnotetext{
- Telegramas de Pignati al conde Ciano, citados por Raguer, H., en «El Vaticano y los católicos vascos durante el primer año de la guerra civils en la obra Guernika: 50 años después (1937-1987), Nacionalismo, República y Guerra Civil. Bilbao, págs. 166-167.

${ }^{9}$ ACG, informe al cardenal Pacelli. Pamplona 1 de enero de 1937.
} 
tudiando la respuesta a la petición española ${ }^{10}$. Con el fin de urgir una contestación, el marqués de Magaz escribió al día siguiente una carta al secretario de Estado insistiendo en el interés del gobierno nacional en el asunto, dado que una condenación explícita de la actuación del PNV tendría como consecuencia la pronta terminación de la guerra en Vizcaya, ahorrando gran número de víctimas. Volvió a recalcar el hecho de la contestación ya dada a un gobierno cuyos intereses no podían equipararse con los españoles, y las propias palabras del cardenal Pacelli sobre los nacionalistas vascos "es indudable que han cometido un delito" ${ }^{11}$.

Tres dias después se recibió en el Palacio de España un comunicado de respuesta. Decía así: «Como a propósito de esto, ya me permití decir la palabra a V.E., aun admitiendo que la unión de los católicos con los comunistas ateos es reprobable y en no pocos documentos de la Santa Sede se ha reprobado... la Santa Sede está examinando esta delicada cuestion y tomando las necesarias informaciones». Se indicaba también que el cardenal primado y Franco habian tratado ya el asunto, demostrando este último una mayor comprensión sobre la delicada situación de la Santa Sede ${ }^{12}$.

El comunicado fue recibido con cierta satisfacción por la diplomacia española en Roma. Si bien no era una contestación afirmativa a lo que se solicitaba, tenía aspectos positivos, sobre todo teniendo en cuenta la lentitud y procedimientos de la Santa Sede. La contestación era escrita y se reconocia que la actitud de los católicos vascos, sin nombrarlos, era reprobable. Esta flexibilidad del general Franco no era exactamente deducible de los informes del cardenal Gomá. La comprensión de la delicada situación de la Santa Sede la habia demostrado el agente oficioso vaticano más que el general Franco. Quizás por ello, el cardenal Pacelli envió copia de este comunicado al cardenal Gomá, junto con el despacho de contestación a las dos cartas enviadas el 1 de enero desde Pamplona. El cardenal Pacelli advertía al cardenal primado sobre la insistencia del marqués de Magaz para que se condenase explícitamente la unión de los vascos con los comunistas ateos y volvía a repetir que en no pocos documentos de la Santa Sede se reprobaba la unión de los católicos con los comunistas y que en el caso español tal unión ya había sido condenada por los obispos de Vitoria y Navarra sin ningún resultado. Ésta y no otra era la causa de la inhibición vaticana. Literalmente el despacho proseguía: «Ahora parece que el Gobierno vasco de Bilbao está más que

\footnotetext{
10 AEESS, despachos 1937, despacho n. ${ }^{\circ} 16$. Roma 8 de enero de 1937.

1 AEESS, despachos 1937. Roma 8 de enero de 1937.

12 AEESS, despachos 1937. Ciudad del Vaticano, 11 de enero de 1937.
} 
nunca controlado por los comunistas que con este objeto se han trasladado desde Cataluña, por lo que es de temer que también un acto de la Santa Sede en este sentido, en las condiciones actuales, quedaría sin efecto, y quizás empeoraria la situación multiplicando las víctimas» ${ }^{13}$.

El marqués de Magaz matizaba algo más. Señalaba que las vacilaciones de la Santa Sede se debian al temor de que los católicos vascos siguiesen aferrados a su conducta, a pesar de la condenación de la Iglesia ${ }^{14}$.

Por ello, el secretario de Estado propuso al cardenal Gomá lo mismo que anteriormente habia propuesto al gobierno italiano: “Otra cosa sería si S. E. el General Franco se decidiera a hacer alguna concesión a las aspiraciones de los vascos, porque se podría entonces tener la esperanza de conseguir inducirles a un acuerdo con el gobierno nacional. La Santa Sede, si fuese llamada a exponer tales condiciones, tomaría la cosa con la más diligente y atenta consideración, porque no desea otra cosa sino que renazca la paz entre sus hijos» ${ }^{15}$. La posible actuación de la Santa Sede tomaba una dirección estrictamente diplomática. El conflicto planteado era insoluble por la vía religiosa, aunque resultase de dificil asimilación en la zona nacional.

Antes de recibir este despacho, el cardenal Gomá hizo pública la carta abierta a Aguirre, tras consultar a diversos obispos, incluido el obispo de Vitoria, quienes le contestaron afirmativamente. El discurso de Aguirre el 22 de diciembre hacía referencia, entre otros asuntos, a que la guerra no era de religión sino de tipo económico arcaico y de contenido social, que la jerarquia católica había callado ante el fusilamiento de sacerdotes y religiosos vascos, «fusilados por el solo hecho de ser amantes del pueblo vasco», ante el destierro violento de sacerdotes vascos y ante la sublevación contra un régimen legalmente constituido.

La carta abierta hacía frente a estas acusaciones, saliendo también al paso de la propaganda que el PNV hacía ya profusamente en la prensa extranjera ${ }^{16}$, intentando no complicar a la Santa Sede y coadyuvar en la acción de los delegados oficiosos - el P. Pereda y Antonio González-

${ }^{13}$ ACG, despacho del cardenai Pacelli, 117/37. Vaticano 11 de enero de 1937.

${ }^{14}$ AEESS, despachos 1937, despacho n. ${ }^{\circ}$ 18. Roma 13 de enero de 1937.

${ }_{15}$ ACG, despacho del cardenal Pacelli 117/37. Vaticano 11 de enero de 1937.

${ }^{16}$ Véanse ACG, informe al cardenal Pacelli. Pamplona 15 de de enero de 1937, donde se señala que «los nacionalistas vascos hayan acudido a una propaganda clamorosa en la prensa extranjera, llegando a fundar en París un periódico titulado Euzko Deya». Véase también el informe al cardenal Pacelli. Pamplona 15 de febrero de 1937, y el despacho $n .{ }^{\circ}$ 11. Roma 21 de diciembre de 1936 del marqués de Magaz. 
Mediación, garantias y seguridades internacionales: ...

en sus conversaciones con el PNV, creyendo que podría influir en un momento de aproximación tras las luchas callejeras producidas en Bilbao y el asalto a las cárceles ${ }^{17}$.

La carta, que fue entregada a Aguirre ${ }^{18}$ fue un rotundo fracaso, prohibiéndose su difusión en Vizcaya policialmente. La causa fundamental de este fracaso fueron unas frases vertidas precipitadamente por el cardenal Gomá sobre la actuación de los sacerdotes en el país vasco, en especial las frases: "Nos resistimos a creer que algunos sacerdotes hayan sido fusilados por el mero hecho de ser amantes del pueblo vasco» y «yo le aseguro, señor Aguirre, que aquellos sacerdotes sucumbieron por algo que no cabe consignar en este escrito".

El cardenal Gomá tuvo que dar explicaciones, incluso a instancias de la Santa Sede al obispo de Vitoria sobre estas frases cuya redacción se prestaba al equívoco ${ }^{19}$. El efecto de esta carta fue así negativo. El gobierno de Salamanca la juzgó benévola en exceso en cuanto a la forma, treinta y un obispos la aprobaron con entusiasmo y Aguirre la juzgó como propia de un «estómago agradecido». La división no podía ser más radical.

En esta situación el cardenal Gomá recibió el despacho anteriormente reseñado de la secretaría de Estado sobre posibles concesiones a los nacionalistas vascos e hizo las gestiones oportunas para averiguar la disposición de ánimo en las más altas esferas militares y políticas. Las negociaciones oficiosas que se venían llevando a cabo desde diciembre por el P. Pereda y Antonio González estaban a punto de darse por finalizadas, pues su fracaso se daba por seguro ${ }^{20}$.

Antonio González hizo llegar al cardenal Gomá las condiciones propuestas para la rendición. Eran las siguientes:

- Respeto a la vida y haciendas de los dirigentes a quienes se les facilitaría la manera de dejar España, a donde no podrían volver mientras no se levantase la prohibición.

- Respeto a la vida de los cuadyuvantes, imponiendo a sus pertenencias un fuerte tributo de guerra, pero permitiéndoseles vivir en España.

\footnotetext{
17 ACG, informe al cardenal Pacelli. Pamplona 15 de enero de 1937 y Pamplona 4 de febrero de 1937.

${ }^{18}$ La carta fue entregada al presidente Aguirre en mano acompañada de una carta personal. No sabemos la razón por la que el dirigente vasco afirmó que le llegó tarde.

${ }^{19}$ ACG, despacho del cardenal Pacelli, 324/37. Vaticano, 29 de enero de 1937 , e informe del cardenal Gomá. Pamplona 13 de febrero de 1937

${ }^{20}$ ACG, informe al cardenal Pacelli. Pamplona 4 de febrero de 1937.
} 
- Respeto a la vida de los milicianos que depusieran las armas, a condición de que no se reintegraran en la lucha, para lo que se tomarian las medidas oportunas ${ }^{21}$.

Estas condiciones sólo eran válidas antes de la caida de Madrid y fueron enviadas por el cardenal Gomá a la Santa Sede el 6 de febrero ${ }^{22}$. Según informe de Antonio González al cardenal Gomá, las negociaciones se habian roto por la intransigencia del PNV, creyendo que con el ejército de 50.000 hombres que habían logrado reunir eran invencibles ${ }^{23}$. A finales de enero se habia dado un plazo para la respuesta del PNV de tres o cuatro días ${ }^{24}$.

Ante lo delicado de la situación, y por las repercusiones que habían tenido los asesinatos realizados en las cárceles de Bilbao, el cardenal Gomá, que en un principio tenía intención de entregar personalmente la propuesta de la secretaría de Estado al general Franco, no se atrevió sino a hacérsela llegar por mediación de una persona muy allegada al general, quien le confirmó que no cabia otra intervención que la del $P$. Pereda ${ }^{25}$.

En efecto, en Salamanca, pocos dias antes, se había respondido a la comunicación enviada por el gobierno italiano, dando cuenta de la respuesta de la Santa Sede a sus gestiones, con estas palabras: «La apreciación que la Santa Sede hace sobre la actitud de los católicos vascos pone de relieve un deficiente conocimiento de la cuestión, ya que jamás los vascos han dado ningún paso cerca del gobierno de Burgos para llegar a un acuerdo, sino que desde el primer momento se lanzaron a la guerra junto con los elementos rojos con los cuales previamente tenían contactos y acuerdos... Al pedirse la intervención enérgica de la Santa Sede se buscaba una solución a lo que los mismos vascos llaman su propia tragedia, ya que derrotados una vez en los frentes de combate,

${ }^{21}$ ACG, carta de Antonio González. San Sebastián 28 de enero de 1937. Nota anónima con las condiciones del bando nacional.

${ }^{22}$ No hemos encontrado duplicado de un posible informe en el meticuloso archivo del cardenal Gomá. El telegrama n. ${ }^{\circ} 5$ del 11 de febrero dice así: Spero saranno giá nelle mani di VER la mia informazione del 4 febbraio e la nota anonima del 6 . Arrivato oggi da visitare Goberno Salamanca trovo venerati dispacci... Agente ufficioso del Governo Salamanca coi Basci mi dice oggi che il termine conceduto per accettare condizioni indicate nella mia nota anonima é stato prorrogato quindici giorni. Segue rapporto.

${ }^{23}$ ACG, informe de un folio, sin fecha.

${ }^{24}$ ACG, informe al cardenal Pacelli. Pamplona 4 de febrero de 1937.

${ }^{25}$ ACG, telegrama a la Secretaría de Estado del Vaticano. Pamplona 17 de febrero de 1937 e informe de la misma fecha. 
Mediación, garantias y seguridades internacionales: ...

están por ser vencidos en su propio territorio por comunistas y marxistas».

A continuación explicaba el campo de intervención solicitado a la Santa Sede «Tal monstruosa alianza, que puede poner término a la existencia de los católicos en Vizcaya, pediamos que fuese desbaratada con un acto de Su Santidad que evitase los sufrimięntos que están obligados a soportar aquellos españoles hasta que sea ocupado (el territorio) por la fuerza de las armas».

Es de notar también la poca importancia que ya se concedia, desde un punto de vista militar, a la actitud que asumiesen los católicos nacionalistas vascos ya que se decia que «no serian seguidos por los rojos que los acompañan». Desde un punto de vista político la visión no era más halagüeña, al considerar que «nada resolvería tan radicalmente el problema separatista como el predominio que los rojos adquieren día a dia sobre los católicos nacionalistas vascos, que terminarán por desaparecer».

Al final se añadía esta irónica coletilla «tal asunto que tiene para nosotros un interés mayor en el orden espiritual que en el material, debe tenerlo también para la Santa Sede por su gran importancia en el orden religioso» ${ }^{26}$.

A su vez, el marqués de Magaz siguió insistiendo. El agente oficioso no había quedado tranquilo con el comunicado de la secretaría de Estado, en especial con el párrafo donde se afirmaba que el cardenal Primado había tratado el asunto con el general Franco, quien habia mostrado una mayor comprensión ante la delicada situación de la Santa Sede. Pensaba que tenía como finalidad escamotear las gestiones que el gobierno le había encomendado realizar para llevarlas a cabo por medio del cardenal de Toledo, quien acababa de publicar la carta abierta a Aguirre que, en su opinión, en vez de amenazas o sanciones canónicas contenía una invitación a la reflexión ${ }^{27}$. El 24 de enero volvió a ser recibido en audiencia por el cardenal Pacelli. El cardenal le aseguró de un modo terminante que nunca estuvo en su ánimo sustraer de la atención del agente oficioso

\footnotetext{
${ }^{26}$ Archivio del Ministero degli Affari Esteri (AMAEl) Santa Sede, 1937, Busta 35, telegramma per corriere $243 \mathrm{R}$. Roma 23 de enero de 1937.

${ }^{27} \mathrm{E} \mid$ texto del informe del cardenal Gomá al cardenal Pacelli de 1 de enero de 1937 dice solamente esto: «dice el Jefe del Estado Español que una desautorización de la conducta de los vascos por parte de la autoridad eclesiástica podría, tal vez, en estos momentos de depresión moral en que se hallan, ser un factor decisivo en el propósito de desistir de la lucha. Con menor motivo, me decia el Generalisimo, la Iglesia intervino en otros tiempos en favor de la causa católica y contra las fuerzas enemigas de la religión (los subrayados son nuestros).
} 
el asunto de los católicos nacionalistas vascos, asunto que seguía en estudio, y que había sido el general Franco quien había mostrado más comprensión que antes en el curso de la conversación con el cardenal Gomá, aclaración que el marqués de Magaz había solicitado.

En consecuencia dedujo que había algo más de lo dicho por escrito y de palabra. En su despacho a la secretaría de Relaciones Exteriores de Salamanca explicó que para la Santa Sede la cuestión no se planteaba en los términos en que la planteó el gobierno. La Santa Sede buscaba la sumisión de los vascos a cambio de una promesa de Franco que satisfaciera los deseos nacionalistas vascos, añadiendo textualmente: «y esto, más que complacer o contestar a la demanda del Gobierno, es desecharla, o, por lo menos, dejando a un lado esa demanda, buscar la sumisión de los católicos vascos por medios políticos, en lo que no parece necesaria, ni tal vez conveniente la injerencia de la Santa Sede». El marqués de Magaz solicitó, por ello, con fecha 28 de enero, instrucciones acerca del sentido en que debía continuar esta negociación ${ }^{28}$.

Por su parte, la secretaría de Estado del Vaticano volvió a insistir con fecha 30 de enero, tras conocer por el informe de 15 de enero del cardenal Gomá la corriente de acercamiento al gobierno nacional de algunos dirigentes del movimiento nacionalista vasco, con un nuevo despacho dirigido al cardenal de Toledo sobre el asunto de las concesiones que el general Franco estaria dispuesto a hacer a los vascos, en particular en el tratamiento reservado a Vizcaya, a su autonomía y a los dirigentes del movimiento nacionalista. De la entidad de tales concesiones dependía el envío o no de una carta pontificia a los vascos del PNV que tendría sin duda efectos beneficiosos, al ser éstos buenos católicos y encontrarse ante una palabra personal del Papa dirigida a ellos exclusivamente ${ }^{29}$.

${ }^{28}$ AEESS, despachos 1937, despacho n. ${ }^{\circ} 25$. Roma 28 de enero de 1937.

${ }^{29}$ ACG, despacho del cardenal Pacelli, 347/37. Vaticano 30 de enero de 1937. De forma paralela, el 11 de febrero, el P. Bivort de la Saudée se acercó a la embajada italiana en Paris para solicitar su apoyo en una mediación entre el gobierno nacional y el gobierno vasco. A este fin expuso que el delegado del gobierno vasco en Paris, José María de Izaurieta, quien habia entrado en contacto con la nunciatura de Paris para sondear la buena disposición de la Santa Sede para favorecer una mediación entre ambos gobiernos, dejando entender que las exigencias de Bilbao para llegar a un compromiso se habían reducido notablemente en los últimos dias, debido a las victorias del general Franco y a la forzada colaboración con los anarquistas y comunistas. Tras las consultas oportunas del nuncio VaIeri en Roma la respuesta fue afirmativa; pero antes de actuar tenian que tener la certeza que existiesen, por parte del gobierno de Salamanca, buenas disposiciones para concluir un acuerdo y que la mediación de una personalidad de alto rango de la Iglesia Católica sería bien aceptada.

Por todo ello se pedía que la representación italiana en España sondeara al gobierno 
El cardenal Gomá visitó con este fin al general Franco el 17 de febrero. Seis días antes había telegrafiado a la secretaria de Estado que el plazo para aceptar las condiciones de rendición telegrafiadas el 6 de febrero, se prolongaba quince días ${ }^{30}$.

El general Franco que estaba sobreaviso por el marqués de Magaz, considerando incluso al cardenal Gomá excesivamente proclive al nacionalismo vasco ${ }^{31}$ no juzgó oportuno ofrecer unas condiciones de rendición en que interviniese la Santa Sede. En Salamanca el ambiente estaba muy caldeado. La actuación en años anteriores de monseñor Tedeschini «participando en algunas reuniones de conjurados contra la monarquía", su disposición a «la componenda» incluso en las zonas más elevadas de la política nacional, — se decía - había tenido como consecuencia dejar a la secretaría de Estado una amplia libertad en la dirección de sus intereses propios en España, allí donde la monarquía ponía límites al poder de la nunciatura, y trataba de conservar intactas las propias prerrogativas en materia de nombramientos de obispos y jerarquías eclesiásticas. Se acusaba a la nunciatura de haber fomentado todos los separatismos locales a través del clero de las regiones más caracterizadas en tal sentido, llegándose a atribuir fines muy tortuosos a la Santa Sede: conseguir un poder siempre mayor sobre la República. Conseguido este encuadramiento regional cada vez más orgánico de las fuerzas católicas era posible vulnerar gradualmente la fuerza del gobierno central en beneficio de la Iglesia. La política del Vaticano en España se resumía en el «divide y vencerás".

Desde el punto de vista del bando nacional, las iniciativas de la Santa Sede en aquellos momentos no eran sino la continuación de aquella po-

de Franco a fin de conocer sus exigencias mínimas para llegar a un acuerdo, al mismo tiempo los sondeos debian tener un carácter estrictamente personal y amistoso. La Santa Sede quería actuar teniendo garantizado el éxito y por ello no se debía nombrar ni a la Santa Sede ni a la nunciatura. Posteriormente a esta gestión llegaron a la secretaria de Estado del Vaticano las condiciones que ponia el gobierno de Franco, cursadas por el cardenal Gomá. (AMAE], Spagna, 1937, Busta 21, telespresso 514/151. Paris 23 de enero de 1937 y telespresso 1060/330. París 13 de febrero de 1937.

${ }_{30}$ Véase nota 22.

${ }^{31}$ AMAEI, Spagna, 1937, Busta 21, telespresso 294/140. Salamanca 17 de febrero de 1937. El despacho concluía que el Gobierno de Franco temía que la persona del cardenal Gomá fuese peligrosa por razón de sus simpatías por los separatismos. Esta disparatada conclusión que no se ajusta ni de lejos a los informes que envió sobre el tema vasco el cardenal Gomá, hay que reiterarlo, se debía a los informes del marqués de Magaz. En este momento con la publicación del Anuario Pontificio de 1937, según informe que fue enviado por despacho $n .{ }^{\circ} 30$ por el marqués de Magaz el 15 de febrero, en el gabinete del general Franco se creyó que se hacia oficial una situación que preludiaba el reconocimiento. Luego esta percepción se consideró equivocada, siendo la cuestión del reconocimiento la que enrareció aún más las deterioradas relaciones entre la Santa Sede y el gobierno de Franco. 
lítica. Franco estaba persuadido de que la Santa Sede tenía horror a la hipótesis de un triunfo bolchevique en España, pero al msmo tiempo temía también la formación de un fuerte gobierno nacional que limitase la influencia y las pretensiones de la nunciatura. El general, no obstante, queria evitar a toda costa una pública polémica con la Santa Sede ${ }^{32}$.

El cardenal Gomá, sin percatarse totalmente del fuego cruzado al que estaba siendo sometido, refirió al cardenal Pacelli los distintos aspectos de la cuestión tal como se veian en la zona nacional, dividiéndolos en dos apartados: El primero, resumen de un informe de Antonio González, y el segundo, resumen de su conversación con el general Franco:

En el aspecto político, señalaba el cardenal Gomá, se hacia una distinción clara entre el gobierno de Euzkadi, PNV y pueblo vasco. EI PNV entre afiliados y simpatizantes no representaba en todo el país vasco la tecera parte del pueblo vasco, por ello, no se admitía que el PNV hablase en nombre del puebo vasco, entendiendo por tal a la gran masa católica de esta región ${ }^{33}$.

Por otra parte la negociación, el pacto o la rendición implicaban el reconocimiento directo o indirecto de un gobierno y unos dirigentes que eran los principales responsables de la situación creada en el país vasco y que ni siquiera habian podido garantizar la vida de los rehenes inocentes que habían sido asesinados en Bilbao. El PNV pretendía pasar a la historia representando al pueblo vasco, incluso haciendo intervenir a la Sarita Sede con miras a ulteriores fines secesionistas a los que no renunciaria jamás ${ }^{34}$.

En cuanto a la situación de hecho con respecto a las negociaciones, tras señalar que la situación militar de Bilbao era desesperada, bloqueado por mar e incomunicado por tierra, exponía el criterio del general Franco. El general le había indicado que las relaciones del PNV con el Frente Popular habian pasado por tres fases: primera de abstención y retraimiento, esperando que los rojos triunfasen sobre los nacionales para luego lograr las ventajas de orden político pactadas con ellos; segunda, en un plano de igualdad o tal vez de superioridad, en la que podían pactar con el gobierno nacional sin peligro para ellos; y tercero de inferioridad por la inmigración de comunistas franceses, catalanes y asturianos. Militarmente -le dijo el general- no era ya posible un pacto

32 AMAEI, Santa Sede, 1937, Busta 35, telespresso 205920. Roma 23 de febrero de 1937.

${ }^{33}$ Esta era también la opinión de la embajada británica en Hendaya, FO 371, 21292, W10179, 21 de mayo de 1937

${ }^{34} A C G$, informe de Antonio González del 11 de febrero de 1937; informe al cardenal Pacelli. Pamplona 17 de febrero de 1937. 
porque significaria su aniquilamiento por las otras fuerzas del Frente Popular. No cabia más que la acción por las armas ${ }^{35}$.

Por estas fechas, mediados de febrero, el representante oficioso del PNV en las negociaciones con el P. Pereda y Antonio González estaba ya plenamente convencido de la inutilidad de la resistencia y de la conveniencia de rendirse. El 15 de febrero marchó de San Juan de Luz a Bilbao con el objetivo de convencer a Aguirre ${ }^{36}$.

La información del cardenal Gomá sobre la posibilidad de negociaciones se cruzó con otro despacho de la secretaría de Estado de la Santa Sede, donde claramente el cardenal Pacelli le decia que el Papa no veía posible la intervención en la forma deseada por el gobierno de Salamanca, pero que a fin de no dejar sin intentar nada que pudiera acelerar la consecución de la paz, se dejaba al criterio del cardenal Gomá la publicación de una carta colectiva del episcopado que enseñase la verdad sobre la cooperación de los católicos con los comunistas ${ }^{37}$.

El cardenal Gomá no lo juzgó oportuno, después de los documentos publicados y su calificación en algún caso de apócrifos por las autoridades del PNV. Reiteró los razonamientos recibidos sobre la posición de minoría en que se encontraba el PNV y la inutilidad ya de una acomodación ${ }^{38}$.

Es a raiz de este despacho de la secretaria de Estado cuando el cardenal Gomá manifestó al cardenal Pacelli que se le habían hecho indicaciones en distintas fechas y desde distintos sectores para que se publicase un documento colectivo acomodado a las circunstancias que atravesaba España. Pensaba que esta toma de posición colectiva aliviaría el mal sabor de boca dejado por la inhibición de la Santa Sede en la cuestión vasca, se daría un carácter más universal a la toma de posición del episcopado y se contrarrestaria la propaganda político-religiosa re-

${ }^{35}$ ACG, informe al cardenal Pacelli. Pamplona 17 de febrero de 1937.

${ }^{36} \mathrm{Idem}$, ibidem. Por estas fechas, el 17 de febrero, el P. Casimiro Morcillo entró en contacto con el canónigo Onaindía en San Juan de Luz, Ilegando en un automóvil prestado por el general Dávila. Le presentó unas propuestas en nombre de "unos nacionalistas vascos» de Donostia para la rendición de Bilbao antes de la caída de Madrid. Al día siguiente recibió la visita del conde de Torrubia con unas proposiciones similares a las negociadas con Julio Jáuregui. El P. Onaindia las hizo llegar a la presidencia del gobierno vasco sin obtener respuesta. (Onaindia, A., Hombre de paz en la guerra. (Buenos Aires, Ekin, 1973) págs. 182184.

${ }^{37}$ ACG, despacho del cardenal Pacelli 470/37. Vaticano 10 de febrero de 1937.

${ }^{38}$ ACG, informe al cardenal Pacelli. Pamplona 23 de febrero de 1937. 
publicana que utilizaba profusamente el tema vasco, tratando de demostrar la tolerancia religiosa republicana ${ }^{39}$.

\section{DESCONFIANZA Y GARANTIAS}

Esta toma de posición del general Franco no dejó completamente cerrado el camino de los contactos que a partir de entonces se desarrollarán a través de múltiples vías de aproximación.

Así el 19 de febrero el embajador italiano en Salamanca telegrafió al conde Ciano que el gobierno de Franco desmentía los rumores que corrian sobre posibles aproximaciones del gobierno de Valencia para conseguir un armisticio o solución de paz al conflicto. Sin embargo confirmaba que llegaban rumores algo genéricos al general Franco de una solución política al problema vasco ${ }^{40}$.

El conde Ciano inmediatamente solicitó detalles de estas negociaciones, Cantalupo respondió con otros dos telegramas. En el primero indicaba que el gobierno del general Franco habia recibido en los últimos dias repetidos mensajes vagos y oficiosos insinuando la posibilidad de un acuerdo. Se esperaba que si se producía una derrota completa de las tropas del Frente Popular en Oviedo, entre las cuales se encontraban varios miles de soldados vascos, cundiría la desmoralización repercutiendo en el gobierno vasco que dimitiria dando paso a un nuevo gobierno que podría presentar una petición formal de rendición ${ }^{41}$. En el siguiente telegrama era más explícito. El gobierno de Salamanca había recibido el 24 de febrero nuevos mensajes oficiosos de Bilbao según los cuales sería posible una petición de rendición cuando Jáuregui consiguiese sustituir al presidente Aguirre. Al mismo tiempo confirmaba que las pérdidas vascas en los combates de los últimos días en Oviedo eran gravísimas ${ }^{42}$.

En efecto, Jáuregui había vuelto de Valencia muy disgustado con la situación encontrada manifestando sus intenciones de hacerse con el poder y romper los lazos entre los vascos y Valencia. Esto quizás puede ponerse en conexión con una noticia no confirmada que circuló transmi-

${ }^{39}$ Idem, ibidem. Véase tambièn, entre otros, el informe al cardenal Pacelli fechado en Pamplona el 3 de marzo de 1937. AEESS, despachos 1937, despacho $n^{\circ}{ }^{\circ} 35$. Roma 4 de marzo de 1937.

40 AMAEI, Spagna, 1937, Busta 21, Telegramma 1239R. Salamanca 19 de febrero de 1937.

${ }^{41}$ Idem, telegramma 2861 R. Roma 22 de febrero de 1937.

${ }^{42}$ Idem, telegramma 1358 R. Salamanca 24 de febrero de 1937. 
tida por Queipo de Llano acerca de la ruptura de relaciones entre Bilbao y Valencia ${ }^{43}$. El gobierno de Valencia estaba al tanto y, posiblemente esta desconfianza les indujera a forzar la acción combinada de las fuerzas del Frente Popular y nacionalistas vascos en el frente de Oviedo ${ }^{44}$.

El 25 de febrero el cardenal Gomá volvió a entrevistarse con el general Franco llevando en su carpeta una serie de asuntos a tratar referentes a la situación de la Iglesia en España, en especial el problema del servicio de los capellanes castrenses ${ }^{45}$ y problemas surgidos por la falta de derogación de la legislación laica republicana. De nuevo volvieron a tratar el asunto del nacionalismo vasco. El general mantuvo sus puntos de vista, añadiendo que no tendria dificultad en que se diera carácter oficial a las negociaciones oficiosas que se estaba manteniendo. El hecho de una rendición sin condiciones - decía Franco-daría a los vascos inmensas ventajas: conservación de Bilbao y otras localidades, respeto a la vida de los dirigentes con la condición de su expatriación, control de las tropas nacionales al entrar en las ciudades y concesión de las mismas facultades de caracter administrativo que se concedieran a otras regiones ${ }^{46}$.

El movimiento a favor de una mediación era cada vez más aparente en algunos medios nacionalistas vascos. También en París, Picavea, propietario del diario vasco parisino Euzko-Deya era favorable por lo menos a una cesación de hostilidades y en tal sentido había aparecido un artículo en el periódico a finales de febrero ${ }^{47}$. Las conversaciones que habian sido llevadas hasta entonces de forma oficiosa y secreta iban a terminar. La Santa Sede que no quería dar un carácter oficial a los sondeos de paz ni a través del cardenal Gomá, ni a través de la nunciatura de París, no creyó oportuno aparecer, pues no estaba segura del éxito de la operación.

Las ofertas de paz siguieron manteniéndose a título estrictamente personal y amigable.

El marqués de Magaz, sin haber recibido instrucciones sobre este tema desde diciembre, volvió a insistir a finales de febrero ante la secretaría de Estado. El cardenal Pacelli tartamudeando y poniéndose muy colorado respondió que el general Franco se habia desinteresado por completo del asunto, según se lo había comunicado el cardenal Gomá, quien

\footnotetext{
43 Idem, telespresso 637/309. Salamanca 22 de marzo de 1937.

44 Idem, telespresso 426/204. Salamanca 3 de marzo de 1937.

${ }_{45}$ Véase sobre este asunto Marouina, A., op. cit., en nota 1, pág. 54 y ss.

46 ACG, informe al cardenal Pacelli. Pamplona 3 de marzo de 1937.

47 AMAEI, Spagna 1937, Busta 21, telegramma 535 R. Salamanca 24 de febrero de 1937.
} 
le escribia con mucha frecuencia y extensión ${ }^{48}$. El marqués de Magaz con fecha 4 de marzo envió a Salamanca un despacho con esta información, comentando las consecuencias que se derivaban de la negociación hasta entonces mantenida. A juicio del agente oficioso su autoridad como representante del gobierno nacional había quedado malparada pues en principio no podía dudar de la veracidad de los cardenales, aunque sí de su buena intención. A continuación, dando por finalizada la negociación, hacía unas consideraciones sobre alguno de los factores que habian jugado en la negociación que había mantenido: La carta abierta a Aguirre de nulos resultados, el miedo de la Santa Sede a intervenir por su convencimiento de que no haría retroceder ni cambiar de conducta a los católicos nacionalistas vascos $y$, sobre todo, el equivoco a que conducía la inhibición de la Santa Sede desde un punto de vista internacional ${ }^{49}$.

Este despacho tendria una honda repercusión en Salamanca. El cardenal Gomá quedaba de nuevo malparado por la alusión del secretario de Estado al desinterés de Franco, cosa que el agente oficioso vaticano había referido de pasada el 4 de febrero, y no parece que reflejase fielmente la posición del general, ni mucho menos la del Cuartel General y el Gabinete Diplomático. Franco, a mediados de marzo estaba indignado y tuvo frases de dura crítica contra la política pontificia llevada a cabo en España. Ya se guardaba muy bien de pedir al Vaticano nuevas intervenciones con respecto a los «separatistas vascos». El problema vasco -decía Franco- se resolvería por las armas, y después la Secretaría de Estado se encontraría en dificultades en el momento que pidiese la acogida del nuncio en Madrid ${ }^{50}$.

Por estas mismas fechas, el cardenal Gomá, desconociendo estas informaciones tan sesgadas en contra de su persona, trató que las conversaciones de paz avanzasen siendo el momento muy propicio. Jáuregui estaba a favor del acuerdo y se creía inminente la toma de Madrid. Por ello, se acercó a San Juan de Luz con la intención de entrevistarse con el canónigo Onaindia, cuya influencia sobre Aguirre era perfectamente conocida. La narración que este hace en sus memorias para explicar las razones de que la entrevista no se celebrara no es muy concluyente sobre las motivaciones ni sobre el contenido. El cardenal que estuvo a pocos

${ }^{48}$ En el informe del cardenal Gomá al cardenal Pacelli de 4 de febrero se dice lo siguiente: «Condoliase el Generalísimo de la actitud de los vascos y, basándose en la religiosidad de los mismos, solicitaba una intervención de la Santa Sede para ahorrar más derramamiento de sangre y la destrucción del país, pero facilmente comprendió no era ni prudente ni factible" (el subrayado es nuestro).

${ }^{49}$ AEESS, despachos 1937, despacho $n .{ }^{\circ}$ 35. Roma 4 de marzo de 1937.

${ }^{50}$ AMAEI, Santa Sede, 1937, telespresso 436/212. Salamanca 14 de marzo de 1937. 
metros de donde conversó el canónigo Onaindía con Francisco Horn, quien actuó de enlace, tuvo que marcharse sin que el canónigo accediera a entrevistarse con él. Según cuenta $\mathrm{P}$. Onaindía en otro pasaje de sus memorias, en este mes de marzo un emisario del cardenal Gomá se puso en contacto con él para indicarle en nombre del cardenal «que hablara al presidente de Euzkadi en tonos firmes y conminatorios de la obligación en que se encontraba de entrar en arreglos con los militares para la rendición de Bilbao" ${ }^{51}$. El canónigo preguntó por «las garantías», a lo que el emisario del cardenal respondió que la garantía sería la persona misma del Primado. Pero esta garantía no pareció suficiente al P. Onaindía.

La cuestión central consistía en que las propuestas aceptadas por Jáuregui no fueron aprobadas en el gobierno vasco por seis votos contra cinco. Probablemente el voto de Aguirre decidió ${ }^{52}$.

Será el 21 de marzo cuando el cónsul italiano en San Sebastián, tras visitar a unos legionarios heridos, tenga una entrevista con el cardenal Gomá. Éste le habló de la cuestión vasca y de los pasos y términos propuestos para llegar a una rendición. El cardenal, después de manifestar sus temores de que el problema vasco pudiera finalizar con una "escabechina" dejó entrever al cónsul que consideraba muy útil una actuación del gobierno italiano para obtener la pacificación ${ }^{53}$. Los preparativos para la ofensiva contra Vizcaya estaban ya ultimándose y los católicos nacionalistas vascos se encontraban en un callejón sin salida. No creían en la posibilidad de una victoria militar sobre su contrincante ni tan siquiera estaban seguros en aquello que hasta entonces habia sido su gran esperanza, la intervención británica. Con todo, tenian a su favor el fracaso de la ofensiva nacional sobre Madrid que en las propuestas de paz habia sido uno de los puntos fundamentales, la rendición sólo sería factible antes de la caída de Madrid, «caido Madrid no había lugar a ningún tipo de

\footnotetext{
51 OnAINDIA, A., op. cit, en nota 36, pág. 212. No son ajustadas las apreciaciones del canónigo Onaindia sobre las intenciones del cardenal Gomá.

${ }_{52}$ Según nota anónima (seguramente de Antonio González, dado el tipo de escritura de la máquina) que se conserva en el archivo del cardenal Gomá, Julio Jáuregui había estado dos veces en Burgos y quería rendirse, pero Aguirre no. El cónsul Cavalletti, en un despacho de 28 de febrero señalaba que corría el rumor que Leizaola habia estado secretamente en Burgos para tratar con Mola (AMAEI, Spagna, 1937, Busta 21, telespresso 426/ 204). Según este despacho las más importantes e influyentes personalidades vascas en e! campo político que hubieran podido apoyar las propuestas de rendición habian sido enviadas al extranjero o a Barcelona.

Sobre el voto de Aguirre véase telespresso 634/307. Salamanca 22 de marzo de 1937 y $637 / 309$ de la misma fecha.

${ }^{53}$ Idem, telespresso 634/307. Salamanca 22 de marzo de 1937. El cardenal explicó al cónsul Cavalletti las propuestas realizadas a través de Julio Jáuregui.
} 
acuerdo» ${ }^{54}$. Pero lo fundamental era que tenían miedo a las represalias. El cónsul italiano, marqués de Cavalletti constataba «el odio terrible» en la zona nacional contra los vascos «traidores a la patria y la religión». Si los nacionalistas vascos - decía en uno de sus informes- consiguieran liberarse de la presión de la izquierda no osarían abandonar las líneas defensivas aterrorizados por la venganza de Franco y de los carlistas, que les acusan de un doble crimen: traición miliar, al estar en la misma trinchera que los rojos, y traición política, al haber permitido una cobertura de tolerancia religiosa en la zona republicana, de cara a los países extranjeros ${ }^{55}$. Las depuraciones que se estaban llevando a cabo en Guipúzcoa, así como las represalias en los primeros momentos de su conquista no eran tampoco unas buenas credenciales ${ }^{56}$.

Por todo esto, tres días antes de iniciarse la campaña de Vizcaya, el cardenal Gomá manifestaba a la Santa Sede que la resistencia a rendirse estaba más acentuada que nunca. Las autoridades no cedian en sus perjuicios contra los nacionalistas vascos, ni éstos disminuían en el fervor de sus actividades propagandisticas. Advertía que no podia hacer gestión alguna, por los informes que habian llegado al general Franco desde Roma poniéndole en guardia contra la política religiosa y la intromisión del Vaticano en los asuntos españoles. Con respecto a la situación de Vizcaya su juicio se resumía del siguiente modo: La causa de aquel pueblo está totalmente perdida, en el orden político y moral ante todo el país ${ }^{57}$. Por otro lado, la prevención contra los sacerdotes simpatizantes del PNV era radical. El cardenal Gomá temía que se reprodujesen aún en mayor grado las sanciones de Guipúzcoa, aunque no esperaba sanciones capitales ${ }^{58}$.

\section{EL FRACASO DE LA INTERVENCIÓN DE LA SANTA SEDE}

El 31 de marzo comenzó la ofensiva en Vizcaya. Desde los aviones se lanzaron numerosas octavillas con esta admonición:

${ }^{54}$ Véase nota 21.

${ }_{55}$ /dem, telespresso 487/234. Salamanca 9 de marzo de 1937.

${ }^{56}$ idem, ibidem.

${ }^{57}$ ACG, informe al cardenal Pacelli. Toledo 28 de marzo de 1937.

${ }^{58}$ Idem, Pamplona 20 de febrero de 1937. Según el cónsul Cavalletti, el clero nacionalista vasco oscilaba entre el temor a los excesos rojos y el temor a la justicia militar de Franco. El bando nacional no facilitaba el cambio de actitud latente que empezaba a notarse entre los nacionalistas vascos $y$, en concreto en el clero, con alguna promesa vaga de respeto a sus vidas. El recuerdo de los 14 sacerdotes vascos fusilados paralizaba cualquier cambio de actitud. Telespresso 567/272. Salamanca 17 de marzo de 1937. 
«Último aviso: He decidido terminar la guerra en el norte de España. Quienes no sean autores de asesinatos y depongan las armas y se entreguen, serán respetados en vidas y haciendas. Si vuestra sumisión no es inmediata arrasaré Vizcaya empezando por las industrias de guerra. Tengo medios sobrados para ello. EL GENERAL MOLA».

La ofensiva fue abordada con una fuerte preparación artillera y bombardeos de aviación. Los aviones bombardearon de modo peculiar algunas poblaciones más inmediatas de carácter claramente militar y Durango, ciudad clave para la penetración hacia Bilbao ${ }^{59}$.

El PNV, con motivo del bombardeo de Durango, envió un telegrama a la Santa Sede denunciando el bombardeo, calificándolo de salvaje, con una enumeración de daños en iglesias y conventos, y un parte de bajas entre la población civil que se elevaban a ochocientas, siendo los muertos ciento ochenta. EI PNV protestaba por esta conducta vandálica al mismo tiempo que reinteraba la adhesión firmisima a las doctrinas de la Iglesia y rendía pleitesia a su Cabeza visible ${ }^{60}$. La Secretaría de Estado del Vaticano agenció el asunto al cardenal Gomá quien, pasados unos dias, envió un informe, reduciendo el número de bajas a doscientas, de las que sólo había veinte muertos, y explicando los resultados de su encuesta, de la que se deducia que existian importantes objetivos militares y eximía de culpa en la destrucción de iglesias y conventos al existir acuartelamientos de tropas en conventos y algunas iglesias habian sido convertidas en almacenes y cuadras. En la última página del informe, citando el testimonio del Vicario de Vitoria, resaltaba que en el ejército formado por los vasco-comunistas, así como en las regiones y ciudades por ellos ocupadas, predominaban "las maneras comunistas de hacer la guerra» con profanaciones de templos e imágenes y el asesinato reciente de siete sacerdotes ${ }^{61}$.

Pero la ofensiva no fue tan rápida como habia sido previsto, y el 7 de abril el sacerdote Casimiro Morcillo, en estrecho contacto con el general Dávila, hacía una nueva aproximación al canónigo Onaidia entrevistándose con él ese mismo día. El P. Morcillo, según cuenta Onaindia dijo venir por iniciativa propia, no conocida del gobierno de Salamanca, y pidió que quedara todo en secreto. Explicó que Bilbao tenía que rendirse para evitar mayores males. Siete días más tarde volvió a verse con él en

\footnotetext{
59 Martinez Bande, J. M., Vizcaya. (Madrid, Editorial San Martín, 1971), págs. 79-80.

50 ACG, telegrama del cardenal Pacelli al cardenal Gomá, adjunto al despacho 1194/37. Vaticano 5 de abril de 1937.

${ }^{61}$ ACG, informe al cardenal Pacelli. Pamplona 20 de Abril de 1937.
} 
París preguntando sobre la contestación de Bilbao. El canónigo Onaindía le dijo que sus proyectos eran demasiado vagos - sospechamos que estaban en línea con las propuestas barajadas desde enero-y que, sobre todo, venia sin un simple documento que le acreditara para tales misiones ${ }^{62}$. Pero ese mismo día, en Salamanca se tenía ya la certeza de que el Reino Unido, manteniendo la cuestión de principio de no reconocer el derecho de bloqueo del gobierno de Salamanca en las costas vascas, por no tener reconocido al gobierno de Franco la cualidad de beligerante, no apoyaria al gobierno de Bilbao viniendo en su ayuda y forzando el cerco ${ }^{53}$. Esta toma de posición causó gran impresión en los círculos diplomáticos de San Juan de Luz.

La diplomacia italiana, después de los sondeos realizados en marzo, y posiblemente con la anuencia de la Santa Sede, trató de cubrir uno de los problemas centrales de las negociaciones oficiosas, el tema de las garantias. Tanto José María de Areilza como el P. Pereda eran de esta opinión. Jose Maria de Areilza confió al cónsul Cavalletti que los vascos aceptarian el ultimátum de Mola, quizás con algunas seguridades para el clero, si se fiasen. Las únicas seguridades posibles debian venir a través de la intervención de un gobierno extranjero. El P. Pereda se encontraba también pesimista. En los últimos dias los nacionales habian fusilado a catorce nacionalistas vascos, uno de ellos en condiciones particularmente crueles e indignas. Estas noticias habian llegado a Bilbao engrandecidas, impresionando aún más al gobierno vasco. Los nacionalistas vascos no créian que Franco les fuese a respetar la vida, punto primero en las propuestas para la rendición ${ }^{64}$. Por estas mismas fechas, el cardenal informó

62 Onaindía, A., op. cit, en nota 51, págs. 185-187. En su narración denota un cierto desconocimiento de todo el entramado de contactos realizados entre el PNV y el gobierno de Franco. No cita por ejemplo, en absoluto, a Julio Jáuregui en los capítulos dedicados a las propuestas, sondeos e intentos de paz y viene a evaluar todo el conjunto de contactos de forma bastante irrelevante.

63 AMAEl, Spagna, 1937, Busta 21, telespresso 946/451. Salamanca 16 de abril de 1937. Según el comandante militar del Bidasoa, Troncoso, negociador de las propuestas de Franco con el Reino Unido, a través de la embajada en Hendaya se tenían pruebas de que el Reino Unido tenía todo preparado para asumir una especie de protectorado sobre el estado vasco. El cónsul Stevenson habia preparado un acuerdo para la cesión de un puerto y de concesiones mineras además de ventajas comerciales, a cambio de la tutela británica. Pero el Reino Unido, puesto en la encrucijada por el gobierno de Franco, se habia resignado por el momento a abandonar prácticamente a los nacionalistas vascos separatistas.

${ }_{54}$ Idem, telespresso 919/440. Salamanca 15 de abril de 1937 y 992/473. Salamanca 20 de abril de 1937. En esta primera aproximación para el ofrecimiento de garantías italianas, el cónsul se puso en contacto, a través de un intermediario de toda confianza, con Andrés de Irujo en Biarriz y le expuso que tenian certeza de que Franco estaba dispuesto a respetar la vida de las poblaciones y de los jefes si se rendian. Andrés de Irujo contestó, sin dudar, que no lo creía. Conocemos - dijo- la palabra de Franco. Sin embargo se mostró muy 
Mediación, garantías y seguridades internacionales: ...

a la Santa Sede que había hecho gestiones ante el general Franco y el gobernador de Guipúzcoa para que no se tomasen represalias, especialmente contra los sacerdotes nacionalistas, pero dudaba mucho de la eficacia de cualquier intervención ${ }^{65}$.

El cónsul Cavalletti recibió información sobre la posible intervención italiana. Los términos del telespresso del embajador italiano en Salamanca dejaban bien claro que el gobierno italiano era favorable a ofrecerse como garantía en caso de rendición, pero que tal eventualidad encontraba dificultades en el hecho de que el general Franco consideraba superflua cualquier intervención extranjera ${ }^{66}$. La secretaria del general Franco les hizo llegar el 25 de abril las condiciones que «habian sido invariablemente propuestas en las diversas gestiones realizadas con idéntica finalidad»:

\section{En el orden penal:}

1. Respeto a la vida y propiedad de los que se rindan y no fuesen criminales.

2. Juicio mediante tribunales para criminales y delincuentes.

3. Los jefes y dirigentes deberían huir al exterior.

4. Confiscación de bienes y juicio por rebelión para los que no se rindiesen.

En el orden politico:

1. Descentralización administrativa con igual tratamiento que las demás regiones.

2. Participación en el Estado a través de los órganos corporativos y sindicales que constituyesen su organización, pudiendo participar en los beneficios y mejoras sociales que el nuevo régimen propusiese tanto al campesino como al obrero.

En el orden religioso:

propicio a considerar la posibilidad de una garantia extranjera.

Empero, en aquel momento el diplomático italiano no podía todavía intervenir. Sólo anunciaba, a través del P. Pereda, quien, a su vez, se iba a poner en contacto con Julio Jáuregui, que Franco había renovado sus seguridades de clemencia. Este era un primer paso de importancia para empezar a crear un clima de confianza.

${ }^{65}$ ACG, informe al cardenal Pacelli. Pamplona 8 de abril de 1937.

${ }^{66}$ AMAEI, Spagna, 1937, Busta 21, telegramma posta. San Sebastián 12 de mayo de 1937. Aquí se citan dos comunicaciones de la embajada en Salamanca para el ofrecimiento de garantias, 12 y 30 de abril. 
La religión católica, unida sustancialmente a España y al nuevo Estado, gozaría de un amplio respaldo y le sería restituido en todo el país el prestigio y el respeto que le habian sido quitados ${ }^{67}$.

Según cuenta el embajador italiano en Salamanca, el P. Pereda llegó a garantizar que Aguirre se mostraba dispuesto a asumir la responsabilidad de una negociación, siempre que Italia diese las garantías pertinentes, pues temian caer en una trampa ${ }^{68}$.

En estas fechas, «anteriores al bombardeo de Guernica», debe encuadrarse también el viaje de Francisco de la Barra, expresidente de Méjico, de París a San Sebastián y Bilbao, regresando a París el 26 de abril con unas propuestas de Aguirre de entablar negociaciones previas: Que no se le considerase como traidor y que las negociaciones se llevasen con el máximo secreto ${ }^{69}$.

Las operaciones militares, mientras tanto, que habían sido paralizadas por la lluvia durante unos días, se reanudaron con mayor brio el veinte de abril. Desde Radio Nacional de Salamanca se apeló a la religiosidad de los vascos haciendo hincapié a la reciente condenación del comunismo por el Papa. Desde los aviones se lanzaron miles de octavillas invitando de nuevo a la rendición. Las octavillas venían firmadas por el general Mola y decian así:

«Vosotros ignorais que el Santo Padre en la reciente encíclica ha condenado el comunismo y cualquier alianza con los comunistas. Como españoles y como católicos tenemos el deber de aconsejaros que abandoneis las armas ante el arrollador avance de las tropas nacionales que están a punto de conquistar toda Vizcaya. Si persistís en vuestra actitud, no podreis evitar la destrucción de vuestras casas y vuestras fábricas».

El texto era más suave que el de la anterior octavilla.

A partir de este momento, las noticias que llegaron a la Santa Sede sobre las operaciones y devastaciones en Vizcaya fueron aterradoras.

El 26 de abril el cardenal Gomá telegrafió a la Santa Sede haciendo notar que según un informador de toda confianza, Eibar había sido totalmente arrasada por los incendios llevados a cabo por los comunistas y separatistas vascos y que el día anterior habian empezado a hacer lo mismo con las iglesias de Bilbao ${ }^{70}$. Las noticias aportadas por el infor-

${ }^{67}$ Idem, Nota, Proposta per la resa di Bilbao, 25 de abril de 1937.

${ }^{68}$ Cantalupo, R., Embajada en España (Barcelona 1951) pág. 186.

${ }^{69} \mathrm{~F}$. de MeEn, "La guerra civil en el Pais Vasco (1936-1937). Hechos y cuestiones de método: una aplicación», en La guerra y la paz cincuenta años después (Madrid, Hermandad de Alfércas provisionales, 1990) pág. 557.

${ }_{70}$ ACG, telegrama cifrado 26 de abril de 1937 . Hemos intentado en los últimos años des- 
mador de toda confianza no esperaron contrastación, si bien en el informe enviado el 1 de mayo, que se prometía a continuación por el telegrama, sólo se hará referencia a Eibar y Guernica ${ }^{71}$ y la intencionalidad de «los incendios». De Bilbao solamente se decia que era de temer igual suerte ${ }^{72}$.

El bombardeo de Guernica, que fue lo que realmente aconteció el 26 de abril, fue denunciado por el presidente Aguirre con un comunicado dirigido a la humanidad entera y aireado posteriormente por la prensa internacional ${ }^{73}$. Con motivo de este bombardeo el canónigo Onaindía llevó a cabo una amplia labor de información. El 28 de abril envió sendos telegramas al cardenal secretario de Estado y a monseñor Múgica. A este último le envió también una carta, cosa que también hizo con el cardenal Gomá. El 5 de mayo se entrevistó con el nuncio en París. Hablaron sobre el bombardeo y la necesidad en que se encontraban de evacuar a los niños. El canónigo manifestó que los niños no se evacuarian si hubiese posibilidad de lograr garantías de respeto a las ciudades abiertas. El nuncio, según la línea mantenida por la Santa Sede, le sugirió la rendición de Bilbao y prometió interesarse por la evacuación de los niños a fin de que fueran acogidos en medios católicos. Ese mismo día el agente oficioso vaticano en la zona nacional le contestó a Onaindía, sin dar demasiado crédito a su testimonio, aconsejándole también la rendición ${ }^{74}$.

Lo que sí cabe afirmar es que «el bombardeo de Guernica contribuyó de forma muy importante a hacer más dificil las negociaciones oficiosas de rendición". Por otra parte, el telegrama del cardenal Gomá contribuyó a una mayor confusión sobre lo que realmente aconteció. La Santa Sede, no obstante, fue acumulando información. El 5 de mayo se recibieron varios informes del cardenal Gomá. El informe fechado el 1 de mayo era

cubrir si esta información podría formar parte de un plan de cobertura y desinformación sobre el bombardeo de Guernica. Los resultados han sido totalmente infructuosos.

${ }^{71}$ Según cuenta el canónigo Onaindía en sus memorias, el cardenal Gomá declaró que había estado en Guernica días después del pretendido bombardeo y pudo comprobar por unos cortocircuitos que los vascos habian incendiado Guernica. Pero de los informes enviados a la Secretaría de Estado no se deduce esto. Solamente habla de incendios. De Irún dice que no quedaba duda alguna y de Eibar afirma que la habia visitado pudiendo comprobar que de la forma en que se produjeron los incendios delataba claramente la tea incendiaria de hombres dispuestos a destruir la ciudad conforme a un plan cuidadosamente estudiado. Añadía que lo mismo cabia decir de las demás localidades destruidas por el fuego, «que ciertamente no había visitado". ACG, informes al cardenal Pacelli. Pamplona 1 y 12 de mayo de 1937.

${ }^{7}$ Idem. Pamplona 1 de mayo de 1937.

${ }_{73}$ Véase OnAindía, A., op. cit en nota 51, págs. 245 y ss, asi como la obra de Southworth, H. R., La destrucción de Guernica (París, Ruedo Ibérico, 1977).

${ }^{74}$ Onaindia, A., op. cit., en nota 51, págs. 246 y ss. 
alarmante. La suerte de Bilbao estaba echada quedando solo pendiente una posible intervención del Reino Unido en la que confiaban los dirigentes nacionalistas vascos. Estaba totalmente descartada ya una mediación con condiciones favorables para los vascos vencidos. Daba datos sobre la desmoralización del ejército vasco; remitió noticias aportadas por el Vicario general de Vitoria sobre asesinatos de sacerdotes no nacionalistas en el tiempo de dominio nacionalista vasco en determinadas zonas; informó sobre la utilización de iglesias, la destrucción de poblaciones, el tráfico de niños, que se calificaba de infame, las gestiones y seguridades aportadas por el gobernador de Guipuzcoa, no suficientes para desbaratar los temores de que se fuera más allá de las medidas de justo castigo, descargando sobre los sacerdotes nacionalistas vascos la furia del vencedor. Estos y otros informes movieron decisivamente a la Santa Sede a intervenir de forma directa en el conflicto, haciendo hincapié en los temores de los católicos nacionalistas vascos ${ }^{75}$.

El marqués de Magaz fue recibido en la Secretaría de Estado el 5 de mayo y se le indicó que Pio XI, sumamente preocupado por la situación de Bilbao, creía podria conseguirse más fácilmente la rendición y ahorrarse muchas vidas si se ofreciesen seguridades de respeto a las vidas de los combatientes al rendirse. El marqués respondió que sólo se fusilaba a los jefes y a los reos de delitos comunes, juzgados en tribunales militares, pero el secretario de Estado insistió en el tema de las seguridades. Este mismo día 5 telegrafió a Salamanca notificando la entrevista, por si Franco quisiera reforzar sus afirmaciones con toda su autoridad ${ }^{76}$. Franco así lo hizo, prometiendo al Papa que en caso de rendición de Bilbao ofrecia el respeto a la vida de todos los combatientes rendidos y la libertad a los que no tuviesen graves responsabilidades ${ }^{77}$. Este telegrama se recibió en Roma el 7 de mayo.

El secretario de Estado al mismo tiempo había enviado un cifrado al cardenal Gomá, que fue recibido el 6 de mayo, anunciándole que era un ardiente deseo del Santo Padre que se empeñase en obtener del general Franco la promesa de respetar la vida de los asediados en Bilbao. Si esto

${ }^{75}$ ACG, informe al cardenal Pacelli. Pamplona 1 de mayo de 1937.

${ }^{76}$ AEESS, legajo 73 , telegrama $n .{ }^{\circ} 11$. Roma 5 de mayo de 1937.

7 ldem, telegrama $n .{ }^{\circ} 6$. Salamanca 7 de mayo de 1937 . El domingo 9 de mayo se entrevistó con el cardenal Pacelli. El dia anterior le habia mandado una carta con las condiciones recibidas telegráficamente de Franco. AEESS, despachos 1937, despacho n. ${ }^{\circ} 69$. Roma 10 de mayo de 1937. Según el marqués de Magaz, el cardenal Pacelli no parecía muy convencido del resultado práctico de esos ofrecimientos. En este despacho, el marqués de Magaz volvió a rebuscar en posibles ocultas intenciones del cardenal Gomá, buscando encontrar supuestos apegos al cargo del cardenal Gomá como representante oficioso. Nada más ajeno a la realidad. 
Mediación, garantías y seguridades internacionales: ...

era concedido, el Santo Padre actuaría ante Aguirre para aconsejarle que cesara la resistencia ${ }^{78}$.

El cardenal Gomá; previo aviso telefónico a Vitoria, donde tenía su residencia el general Mola, fue al hotel Frontón a la caida de la tarde el 7 de mayo, entrevistándose con el general. La entrevista fue muy cordial y se acordaron las siguientes bases de rendición:

1. Las autoridades militares tendrán el máximo empeño en conservar intacta la ciudad.

2. Se darian facilidades para la salida de los dirigentes.

3. Se dará garantía plena de que las tropas no cometerán ningún exceso.

4. Se dará libertad absoluta a los soldados y milicianos que se entreguen con las armas, siempre que no hubiesen sido desertores del Ejército nacional durante las operaciones.

5. Se someterá a los tribunales de justicia a los que sean reos de delitos contra el derecho de gentes, devastaciones y saqueos.

6. Se considerarán desertores los jefes del ejército contrario y se someterán a un tribunal que obrará con criterio benévolo ${ }^{79}$.

Al terminar la conversación, el general Mola telefoneó al general Franco y leyó las condiciones acordadas. Franco las aprobó, suavizando la sexta, y añadiendo otros dos puntos, en función de las propuestas anteriormente ofrecidas por el P. Pereda y reiteradas al embajador italiano el 25 de abril.

La sexta quedaba redactada del siguiente modo: Respeto a la vida y haciendas de los que se entreguen de buena voluntad, incluso a los jefes militares.

Los otros dos puntos eran los siguientes:

7. En el orden político, se concederá a Vizcaya la descentralización administrativa en forma análoga a otras regiones favorecidas.

8. En el orden social, se ofrece una justicia progresiva dentro de las posibilidades de la economía nacional, según el espíritu de la encíclica Rerum Novarum.

78 ACG, telegrama $n .8$, recibido el 6 de mayo de 1937.

79 ACG, informe al cardenal Pacelli. Pamplona 8 de mayo de 1937. 
Las condiciones serian efectivas si se llegaba a una rendición inmediata, previa a la ruptura del cinturón de hierro ${ }^{80}$.

El cardenal Gomá el 7 de mayo puso un telegrama cifrado a la secretaria de Estado, transmitiendo las condiciones propuestas, advirtiendo al cardenal Pacelli que las operaciones militares eran tan rápidas que en el plazo de tres días se lucharia en el cinturón de hierro. Urgía aconsejar la rendición también por el peligro de que los nacionalistas vascos fuesen superados por los anarquistas, dadas las luchas existentes ya entre ellos ${ }^{81}$.

El cardenal, en su deseo de facilitar el cese de hostilidades y la gestión de la Santa Sede ante Aguirre, marchó a San Juan de Luz el mismo día 7 para tratar de entrevistarse con el canónigo Onaindia, cuya influencia sobre Aguirre era conocida por los agentes mediadores ${ }^{82}$. Llegó con el canónigo Despujol a la puerta de Villa Subiburu, residencia de la familia de José Camiña donde se hospedaba el canónigo Onaindia, pero éste acababa de salir para Paris y no pudo llevarse a cabo la entrevista.

Una vez de regreso en Pamplona, el cardenal Gomá envió a la secretaría de Estado un extenso informe ${ }^{83}$ confirmando su telegrama y ampliando los extremos de la conversación con el general Mola.

Entretanto, el general Franco ratificó sus criterios haciendo pública una proclama dirigida a Vizcaya, conteniendo los puntos acordados entre el cardenal Gomá y los generales Mola y Franco. La proclama fue arrojada por la aviación sobre aquella provincia. Fué leída con avidez por los habitantes de Bilbao entre los que se originó una fuerte corriente de opinión favorable a la rendición de la ciudad. Esta fue la información que le llegó al cardenal Gomá, junto con la noticia de la asunción por Aguirre del mando directo de las operaciones militares, sin saber claramente si habia tenido lugar con miras a facilitar la rendición o cediendo a indicaciones superiores ${ }^{84}$.

an Idem, ibidem.

${ }^{81}$ Idem, telegrama n. 12 . Vitoria 7 de mayo de 1937.

82 Idem, informe al cardenal Pacelli. Pamplona 8 de mayo de 1937. El cardenal Gomá explicó la razón de este intento de ia siguiente manera: «Personas conocedoras de los políticos que dirigen el movimiento nacionalista me aseguran que entre ellos, especialmente entre el Sr. Jáuregui y el Sr. Aguirre, ha habido estos dias durisimas discusiones, hasta faltarse mutuamente en acaloradas disputas. Jáuregui está empeñado en la rendición. Sostiene a Aguirre especialmente el canónigo Don Alberto Onaindia, que lo es de la catedral de Valladolid... Vista la gravedad de la situación, y creyendo interpretar los sentimientos de caridad de la Santa Sede, quise hablar con el Sr. Onaindía para reducirle a mejor consejo».

${ }^{83}$ ldem, ibidem.

84 Idem, informe al cardenal Pacelli. Pamplona 12 de mayo de 1937. 
La Santa Sede finalmente se decidió a actuar directamente y telegrafió las condiciones de los generales Franco y Mola al presidente Aguirre, exhortándole en nombre del Santo Padre a que tomara en atento y solícito examen las propuestas, con el deseo de que el conflicto cesara. El 8 de mayo el telegrama, sin cifra alguna, llegó a Barcelona, vía París, y ese mismo dia fue remitido a Valencia, llegando a manos de Largo Caballero, quien ordenó que no se cursase el telegrama. Al día siguiente es posible que el asunto se tratase en un consejo de ministros al que no asistió Manuel de Irujo. No obstante, ese mismo dia, Aguirre cursó un telegrama a Manuel de Irujo señalando que suponían que el telegrama de Pacelli sería apócrifo y que no estaban dispuestos a rendirse. Con todo, el 10 de mayo se solicitó a la Santa Sede desde Bilbao la retransmisión del mensaje al no haberse recibido allí. Simultáneamente se publicó una nota de desmentido, negando que la secretaría de Estado del Vaticano se hubiera dirigido al gobierno vasco y afirmando que las noticias aparecidas en la prensa no se correspondian con la verdad, siendo apócrifo el telegrama y una maniobra más de los agentes de espionaje internacional.

Sorprendentemente, el 12 de mayo, el cardenal Pacelli volvió a repetir la misma operación, enviando a París el telegrama «en claro» que, a su vez, fue remitido a Barcelona y de aquí pasó a Valencia, donde de nuevo quedó retenido, siendo discutido ásperamente en un consejo de ministros.

Paralelamente el nuncio en París trató de ponerse en contacto con Alberto Oanindía el 10 de mayo y, al no conseguirlo, lo hizo con Francisco de la Barra, quien al día siguiente entró en contacto con el delegado del presidente del gobierno vasco en París, Francisco de Basterrechea. Éste envió el 11 un telegrama a Aguirre exponiendo las gestiones de Francisco de la Barra de parte de un «personaje extranjero propósitos conocido eufemismo, entendiendo dicho señor ventajas, aunque debe considerarse aspecto Valencia y garantías tomar su caso" Basterrechea se pronunciaba contra una solución parcial y separada.

Tal como hemos expuesto, Aguirre conocía al menos desde enero de 1937 las propuestas que el gobierrio de Franco ofrecia, propuestas que se habian ido reiterando por unos $u$ otros de forma oficial y oficiosa. Esto explicaría el contenido aparentemente poco claro de este telegrama. Creemos que el estudio de Fernando de Meer sobre este tema ${ }^{85}$ junto con los nuevos datos aportados en este trabajo sobre la suerte de las propuestas de acomodación con los católicos del PNV son suficientemente

85 Véanse MEER, F. de, op. cit., en nota 69, págs. 549-568 y del mismo autor, «Mediación del Vaticano para la rendición de Bilbao», Historia 16, 174 (1990) págs, 12-21. 
concluyentes para poder considerar que el presidente Aguirre y miembros destacados del PNV hicieron caso omiso a la propuesta de la Santa Sede. No parece admisible otra explicación, salvo que se admitiera una más notable impericia y falta de sentido político, después de solicitarse desde Bilbao la repetición del telegrama y el revuelo que la prensa creó con este motivo, independientemente de otros telegramas y manifestaciones del propio presidente Aguirre, contrarios a la rendición.

Cabe incluso añadir algunos datos más.

El 10 de mayo se encontraba el canónigo Onaindía en Bilbao y el 11 pasó a San Juan de Luz para encauzar el asunto de la llegada de refugiados por mar desde Bilbao. Aquí mantuvo una conversación con un emisario del cardenal Gomá, seguramente el canónigo Lorea. Según el testimonio de Onaindía al cónsul Cavalletti, el cardenal Gomá le había mandado decir que él debia asumir la completa responsabilidad de la continuación de la guerra, pero el cardenal estaba equivocado. A pesar de su amistad con Aguirre no tenía toda la influencia que se le atribuía, dado que en el gobierno de Bilbao colaboraban también otros partidos distintos del PNV ${ }^{86}$.

Empero los puntos resumidos de lo manifestado por Onaindia al emisario del cardenal Gomá, tal como éste los hizo llegar a la Santa Sede fueron los siguientes:

1. Los nacionalistas vascos ni pueden ni deben rendirse, sino que deben resistir, incluso hasta la destrucción de Bilbao.

2. Aguirre es de tal condición que esperará impávido en su puesto hasta el último momento, y las tropas nacionales le encontrarian ante su mesa de despacho.

3. Las presuntas negociaciones para el logro de una rendición honrosa de Bilbao son demostración palmaria de la debilidad de los nacionales que se ven obligados a pedir la paz ${ }^{87}$.

Esta respuesta corrobora que el clima en Bilbao era netamente contrario a la rendición, sintiéndose seguros.

Por otra parte, en el telegrama de Basterrechea a Aguirre, aparece junto con la cuestión de la paz separada de Valencia, el punto de las

\footnotetext{
${ }^{96}$ AMAEI, Spagna, 1937, Busta 21, telegramma posta 974. San Sebastián 12 de mayo de 1937. Véase también la nota 82.

${ }^{87}$ ACG, informe al cardenal Pacelli. Pamplona 14 de mayo de 1937. A juicio del cardenal Gomá, las esperanzas de una solución pacífica eran escasisimas.
} 
garantías que venía estando en primer plano. Pero incluso este punto de las garantías podía haber quedado resuelto, pues el cónsul italiano en San Sebastián recibió de su embajada en Salamanca una comunicación informándole que el gobierno italiano ofrecía su garantía a los vascos en caso de la rendición de Bilbao, para lo que necesitaban una petición del PNV, pues el general Franco consideraba superflua una garantia extranjera ${ }^{88}$.

El 10 de mayo el cónsul se entrevistó con Francisco Horn en San Juan de Luz, "enlace con el gobierno de Aguirre en todas las negociaciones que se han desarrollado en los últimos tiempos». Horn comentó que el general Mola le había hecho llegar una nota el 2 de mayo donde se repetían las promesas de respetar vidas y bienes, pero que no habia podido tomarse en seria consideración porque faltaban garantías prácticas. Horn le puso en contacto con Onaindía y pudo desarrollar las gestiones encomendadas. Onaindia se mostró interesado por la propuesta italiana (casi con seguridad realizada por influencia de la Santa Sede), temiendo sobre todo una intervención alemana que sería la catástrofe religiosa y económica del país vasco, y ahi estaba el ejemplo de la destrucción de Guernica. En esta conversación, le informó también de la gestión realizada ese mismo dia por un emisario del cardenal Gomá y añadió que sería útil que se viera con Doroteo Ziaurriz, presidente del PNV, quien también se encontraba en Francia por el asunto de los refugiados. El cónsul aunque no tuvo la oportunidad de encontrarse con el presidente del PNV, sí lo hizo con Andrés de Irujo, quien se mostró algo reservado ante la propuesta, si bien afirmó que una intervención extranjera tendria algunas posibilidades de éxito. Pero insistió en que Bilbao no habia perdido la guerra y que para obtener la rendición sería necesaria la concesión de una autonomía. Añadió que "otros gobiernos estarían actuando en tal sentido».

El 12, a la una de la madrugada, era despertado el cónsul en su domicilio en San Sebastián. Un emisario de Onaindia le manifestó que tenía urgencia de verle por la mañana.

De nuevo Francisco Cavalletti marchó a San Juan de Luz y tuvo una segunda conversación con Onaindia, quien le dijo que Doroteo Ziaurriz había encontrado la garantía italiana sumamente interesante, siendo «la primera posibilidad concreta para una pacificación que se había presentado desde el comienzo de la guerra, "habiendo sido todas las demás vagas o inaceptables». 1937.

Aв AMAEl, Spagna, 1937, Busta 21, telegrama posta 974. San Sebastián 12 de mayo de 
Como debia marchar inmediatamente a Bilbao en un aeroplano para conversar con Aguirre sobre este asunto, le solicitó una repetición de los puntos de la propuesta, que fueron puestos por escrito ${ }^{89}$. Según el cónsul italiano, Onaindía le dijo de parte de Ziaurriz que deseaba vivamente que se acercase a ver a Aguirre para lo que Onaindía solicitaría de Aguirre un pasaporte para viajar secretamente a Bilbao. Aunque no tenía nada en contra, el cónsul indicó que necesitaba la autorización de Roma ${ }^{90}$.

Onaindía se entrevistó con Aguirre y al día siguiente volvió a San Juan de Luz con una nota de cinco puntos:

1. El presidente de Euzkadi agradece el interés que Italia manifiesta en esta gestión por el pueblo vasco.

2. Felicita como buen político a quien haya visto el problema vasco con el conjunto del problema español.

3. No puede haber diálogo sobre «rendición».

4. El presidente de Euzkadi afirma con optimismo que cuenta con su pueblo y quizá con algo más.

5. (Le) recibirá a Ud. con todas las atenciones personales que se merece ${ }^{91}$.

A nuestros propósitos es interesante constatar los puntos 3 y 4: no cabía hablar de rendición, y contaban con su pueblo y algo más. Esta seguridad de Aguirre bien puede ponerse en conexión con «la actividad del cónsul británico en Bilbao, Stevenson, quien, por otra parte, recibió unas directrices del gobierno británico de no apoyar la rendición» ${ }^{92}$.

${ }^{89}$ Idem, ibidem. La nota de Mola de 2 de mayo estaba dividida en cuatro puntos. E! cuarto decia asi: El mando militar ha ofrecido respetar las vidas y haciendas en cuantos reconozcan su autoridad, siempre que no hayan incurrido en delitos comunes. Reitera su promesa, y asegura que sus tropas no cometerán atropellos.

Nada se decía sobre las responsabilidades de los dirigentes. Véase el documento de garantia italiana para la rendición en ONAINDIA, A., El Pacto de Santoña (Bilbao, Editorial Laiz, 1983), págs. 33 y 34.

${ }^{90}$ El testimonio de Onaindía háce recaer sobre el cónsul Cavalletti el deseo de ver a Aguirre, mientras que según el testimonio italiano, la iniciativa provenia de Ziaurriz. Esto parece lo más convincente. Véase AMAEI, Spagna 1937, Busta 21, telegramma posta 974 , cit.

9: Onaindia, A., op. cit., en nota 89, pág. 35.

92 Consideramos este punto esencial para entender los planteamientos del PNV. Véase F.O. 371, 21292, W9780. Esto puede explicar más fehacientemente la enemiga del bando nacional contra el cónsul británico Stevenson, cuya actitud en favor del nacionalismo vasco no se ponía en duda ni por los diplomáticos franceses ni por el propio embajador Harry 
Con ello, queda claro, que aún solventando el asunto de las garantias, la solución propuesta no era factible por las seguridades que los nacionalistas vascos tenian o creian que podían tener del Reino Unido. Las negociaciones continuaron tras una pausa debido a que Cavalletti recibió una indicación de que suspendiera los contactos pues Mussolini trataría el tema directamente con Franco ${ }^{93}$.

El 27 de mayo el cónsul italiano solicitó de Onaindía algunas aclaraciones al punto referente a la no aceptación de la rendición y si habia algún extremo sobre el que iniciar el diálogo sobre la apertura de contactos por la vía humanitaria, mediante un canje de prisioneros vascos e italianos y señaló la conveniencia de que solicitaran la intervención de Mussolini en orden a humanizar la guerra, dando algún contenido político a la propuesta ${ }^{94}$.

Sorprendentemente, el 4 de junio, el cónsul italiano recibió de Onaindía el siguiente telegrama proveniente de Aguirre: «Sobre asunto que le interesa comunicole que gobierno ha acordado canje cuatro prisioneros italianos en nuestro poder con cuatro súbditos ingleses». Onaindía muy molesto por este canje, donde no aparecían los prisioneros vascos, recibió a su vez de su interlocutor informaciones y reflexiones sobre la situación de Bilbao y la conveniencia de que el gobierno vasco solicitase la intervención de Mussolini, pues no podian contar con el apoyo inglés, dado que el Reino Unido buscaba acercarse a Franco.

A este fin, le mostró las dos circulares entregadas a la prensa de la zona nacional donde se prohibia cualquier ataque al Reino Unido.

Onaindía quedó «profundamente impresionado» por los documentos presentados y señaló que iría a ver a Aguirre para pedirle las oportunas explicaciones y aclaraciones a los cinco puntos entregados con anterioridad que, según Onaindia, eran la única respuesta oficial del gobierno vasco dada hasta entonces a los múltiples contactos con intermediarios extranjeros 0 de Salamanca ${ }^{95}$.

A partir de este momento los contactos con los italianos se desarrollaron con poca fluidez en función del avance de las tropas nacionales

Chilton. Fue acusado posteriormente de persuadir a las autoridades vascas a adoptar una política que meramente prolongó la agonía de la población, aunque en su descargo, el Foreign Office destacó que habian tenido que frenarle, pues se habia ofrecido para negociar la rendición de Bilbao, y el hecho de que habia incluido en la evacuación de refugiados una proporción de rehenes políticos. (Véase FO 371, 21296, W12624.

${ }^{83}$ OnAindíA, A., op. cit en nota 89, pág. 38.

${ }^{94}$ Idem, pág. 39.

95 AMAEI, Spagna, Busta 20, telegramma posta 1233. San Sebastián 4 de junio de 1937. 
sobre Bilbao. Ninguna gestión efectiva quiso el presidente Aguirre que se realizase, hasta que Ajuriaguerra solicitó de Onaindia que hablase con el cónsul italiano en orden a la salvaguardia de las vidas de la población civil cuando las tropas de Franco entrasen en Bilbao. Hay también que señalar que paralelamente a esta intervención italiana. Francisco de la Barra expuso a monseñor Pizzardo, a su paso por París con motivo de la coronación del rey Jorge $\mathrm{VI}$, que Aguirre desengañado estaba dispuesto a llegar a un acuerdo con el general Franco con dos condiciones, que se le considerase como un adversario leal y que las negociaciones se llevasen con el más absoluto secreto. El viaje de monseñor Pizzardo tuvo una larga duración, del 6 al 24 de mayo. No sabemos en este momento si la entrevista entre Francisco de la Barra y monseñor Pizzardo tuvo lugar a la ida o a la vuelta de su viaje a Londres. El caso es que, frente a otras opiniones, en la entrevista en Lourdes entre el cardenal Gomá y monseñor Pizzardo, este asunto no fue ni expuesto ni desde luego abordado en la conversación. Incluso más, de las notas manuscritas dejadas por el cardenal Gomá se deduce que el Vaticano ya había dejado de considerar factible una solución de compromiso. El apunte a mano es contundente «sono gia iudicati» (ya están juzgados) ${ }^{96}$.

La propuesta fue hecha por monseñor Pizzardo al marqués de Magaz en Roma el 29 de mayo y fue transmitida telegráficamente el 30 desde el palacio de España ${ }^{97}$.

El 31 desde Salamanca se envió a Roma y al cardenal de Toledo la respuesta a la proposición condicionada de Aguirre en los siguientes términos:

La negociación se llevaria con toda reserva. La parte personal era cuestión secundaria, pero en lo que se refería a Aguirre no podia eximirsele de la sanción adecuada que solamente podría eludirse por la expatriación. No cabían ya dilaciones en las conversaciones, dada la situación de Bilbao, y una vez que se desencadenase la última ofensiva sería muy difícil ya negociar ${ }^{98}$.

La contrapropuesta fue presentada por el marqués de Magaz a monseñor Pizzardo, quien señaló que consideraba inútil toda gestión que no

${ }_{96}$ ACG, nota manuscrita de la conversación con monseñor Pizzardo.

97 AEESS, legajo 73, telegrama 17. Roma, 30 de mayo de 1937.

${ }^{9} \mathrm{ACG}$, Carta de Fidel Dávila, sin fecha, y telegrama n. ${ }^{\circ} 13$ del cardenal Gomá a la Secretaría de Estado del Vaticano, 31 de mayo de 1937. 
empezara por reconocer a Aguirre como un adversario leal. Esta respuesta fue telegrafiada el 4 de junio ${ }^{99}$.

Después de lo anteriormente expuesto, consideramos que esta propuesta era ya obsoleta, correspondiente a la dinámica anterior al bombardeo de Guernica.

Estando a punto de conquistarse Bilbao, el cardenal Pacelli envió un telegrama al cardenal Gomá, encargándole que apelara en nombre del Divino Redentor y a la fe de católico de Franco para que las negociaciones para la rendición de Bilbao se finalizasen, evitándose toda humillación inútil y el derramamiento de sangre ${ }^{100}$.

Franco manifestó que actuaría con absoluta benignidad. No obstante las actuaciones posteriores no se ajustaron a estas palabras en a integridad ${ }^{101}$.

${ }_{99}$ AEESS, legajo 73, telegrama 20. Roma, 4 de junio de 1937.

100 ACG, telegrama n. ${ }^{\circ} 13$ del cardenal Pacelli. Vaticano, 18 de junio de 1937.

${ }^{101}$ Esta fue la opinión, por ejemplo, del P. Pereda, quien no podia ser acusado de simpatías hacia el nacionalismo vasco, sobre el tratamiento inferido al clero vasco. AMAEl, Santa Sede, 1937, Busta 14, telespresso 1885. 